\section{Situação dos municípios do \\ estado de São Paulo com \\ relação à compra direta de \\ produtos da agricultura familiar \\ para o Programa Nacional de \\ Alimentação Escolar (PNAE)}

\section{Situation of the municipalities of \\ São Paulo state in relation to the purchase of products directly from family farms for the National School Feeding Program (PNAE)}

\section{Betzabeth Slater Villar}

\section{Flavia Schwartzman}

\section{Bruna Lourenço Januario}

\section{Jamile Fernandes Ramos}

Departamento de Nutrição da Faculdade de Saúde Pública da Universidade de São Paulo, Brasil.

Correspondência: Bruna Lourenço Januario. Departamento de Nutrição, Faculdade de Saúde Pública, Universidade de São Paulo. Av. Dr. Arnaldo, 715, Cerqueira César, São Paulo, SP, Brasil CEP 01246-904. E-mail: brulj@usp.br

\section{Resumo}

Introdução: Em 2009, foi aprovada a Lei 11.947, a qual dispõe sobre o atendimento da alimentação escolar e consolida a vinculação da agricultura familiar com o Programa Nacional de Alimentação Escolar (PNAE), ao estipular que no mínimo $30 \%$ do total dos recursos financeiros repassados pelo Governo Federal aos estados e municípios deverão ser utilizados na aquisição de gêneros alimentícios diretamente da agricultura familiar. Objetivo: Caracterizar a situação dos municípios do estado de São Paulo com relação à compra de produtos diretamente da agricultura familiar após a aprovação da Lei 11.947. Método: O diagnostico foi realizado nos meses de junho a agosto de 2011 por instituições vinculadas à Comissão Estadual Intersetorial da Alimentação Escolar (CEIA). Para o levantamento foi utilizado questionário e realizada entrevista telefônica com os representantes dos 645 municípios. Resultados: Em um total de 613 municípios foi possível obter as seguintes informações: 47\% (288) já haviam realizado as compras locais pelo menos uma vez, em todas as suas etapas. Dos $325 \mathrm{mu}-$ nicípios que não efetivaram o processo em todas as fases, $57 \%$ não haviam publicado a chamada pública; $37 \%$ publicaram, mas não assinaram o contrato de aquisição; $2 \%$ publicaram, assinaram o contrato, mas não haviam recebido os produtos; $\mathrm{e} \%$ publicaram, receberam os produtos mas ainda não haviam pago os agricultores. Conclusão: Os resultados obtidos revelam que aproximadamente $50 \%$ dos municípios avaliados estão em situação positiva com relação às compras locais para o PNAE. Entretanto, o número de municípios que não publicou a chamada ou que não assinou o contrato é ainda importante, merecendo atenção dos setores envolvidos.

Palavras-chave: PNAE. Alimentação escolar. Desenvolvimento local. Agricultura familiar. Política pública. Chamada pública. 


\section{Abstract}

Introduction: In 2009, Law 11,947 was passed, which provides for the care of school meals and consolidates the linkage of family farming with the National School Feeding Program (PNAE), by stipulating that at least $30 \%$ of the total financial resources granted by the Federal Government to the states and municipalities should be used for the acquisition of food directly from family farmers and rural entrepreneurs family or their organizations. Objective: To characterize the situation of the municipalities of São Paulo state in relation to the acquisition of products directly from family farmers after approval of Law 11,947. Method: The diagnosis was carried out in the months of June to August 2011 by institutions linked to the Intersectoral School Feeding State Commission (CEIA). For the survey, a questionnaire was used and telephone interviews were conducted with representatives of the 645 municipal districts. Results: It was possible to obtain the following information for a total of 613 municipalities: 47\% (288) had already made local purchases at least once in all its stages. Of the 325 municipalities that do not conducted the process at all stages, $57 \%$ had not published a public call; $37 \%$ published but had not signed the purchase contract; $2 \%$ published a call, signed the contract but had not received the products; and $4 \%$ published at least one call, received the products but had not yet paid the farmers. Conclusion: The results show that approximately $50 \%$ of the municipalities evaluated are in a positive situation in relation to the local procurement for PNAE. However, the number of municipalities that did not publish the public call or not signed the contract is still important and deserves attention of the sectors involved.

Keywords: PNAE. School feeding. Local development. Family farming. Public policy. Public call.

\section{Introdução}

O Programa Nacional de Alimentação Escolar (PNAE), uma das políticas públicas mais antigas do país e um dos maiores programas de alimentação escolar do mundo, tanto em número de pessoas atendidas quanto em recursos alocados, atualmente constitui importante estratégia de Segurança Alimentar e Nutricional (SAN), ao promover o Direito Humano à Alimentação Adequada (DHAA) através da alimentação escolar, assim como de várias ações que contribuem para que se possa atingir as metas dos Objetivos de Desenvolvimento do Milênio (ODM).

Durante a sua existência, o PNAE passou por diversas estruturações que levaram a avanços, dos quais um dos mais importantes é o apoio ao desenvolvimento local sustentável, com incentivos para a aquisição de gêneros alimentícios diversificados, produzidos em âmbito local, e o respeito aos hábitos alimentares regionais e saudáveis.

Em 2009 foi aprovada a Lei 11.947, a qual dispõe sobre o atendimento da alimentação escolar e consolida a vinculação da agricultura familiar com o PNAE, ao estipular que no mínimo $30 \%$ do total dos recursos financeiros repassados pelo Governo Federal aos estados e municípios deverão ser utilizados na aquisição de gêneros alimentícios diretamente da agricultura familiar e do empreendedor familiar rural ou de suas organizações, priorizando-se os assentamentos da reforma agrária, as comunidades tradicionais indígenas $\mathrm{e}$ as comunidades quilombolas.

A operacionalização desta política é bastante complexa, pois envolve diversos setores do governo e da sociedade, nos âmbitos municipal, estadual e federal e, para que essa operacionalização ocorra de forma adequada, é fundamental que existam condições favoráveis nas diversas esferas que estão envolvidas, tanto com a alimentação escolar como com a agricultura familiar.

Como a lei é relativamente recente, o processo de operacionalização encontra-se 
ainda em fase de implementação em vários municípios do país. Neste sentido, considerou-se importante realizar um diagnóstico situacional a respeito do processo de implementação das compras locais pelo PNAE nos municípios do estado de São Paulo.

\section{Metodologia}

O levantamento foi realizado nos meses de junho a agosto de 2011 por instituições vinculadas à Comissão Estadual Intersetorial da Alimentação Escolar (CEIA). A Faculdade de Saúde Pública/USP participou como instituição colaboradora.

Para a obtenção dos dados foi desenvolvido um questionário que avaliou a situação do município em relação à compra de produtos diretamente da agricultura familiar, de junho de 2009 a agosto de 2011.

O levantamentos de dados foi realizado por entrevista telefônica e os entrevistados foram os responsáveis pela alimentação escolar das prefeituras ou gestor que pudesse responder as perguntas. A entrevista telefônica durou, em média, 10 minutos.

$\mathrm{O}$ questionário foi aplicado, de forma padronizada, por diferentes entrevistadores de distintas instituições. Algumas das questões eram abertas, como cargo e instituição do informante, número de chamadas públicas realizadas e percentual dos recursos do Governo Federal utilizados para a compra da agricultura familiar, por meio de chamada pública, em 2010. A questão referente à realização ou não de chamada pública era fechada, tendo como respostas as opções sim ou não. Para a questão referente aos recursos utilizados para a compra da agricultura familiar, na informação foi registrada o percentual sem necessidade de se fazer cálculos.

Cabe salientar que houve 95\% de adesão dos municípios do estado de São Paulo ao levantamento. Todas as perguntas foram respondidas; entretanto, para a questão referente aos percentuais gastos, nem sempre o entrevistado sabia informar.

\section{Resultados}

Dos 645 municípios do Estado de São Paulo, a entrevista telefônica foi realizada com sucesso em 613 (95\%). Nos demais 32 municípios (5\%), não foi possível contatar um informante qualificado que pudesse fornecer as informações de forma fidedigna.

Do total dos 613 municípios avaliados, 47\% (288) realizaram a implementação das compras locais em todas as suas etapas, pelo menos uma vez, desde 2009; isto é, publicaram pelo menos uma chamada pública, receberam os produtos e realizaram o pagamento aos produtores.

Dos 325 municípios que não efetivaram o processo em todas suas fases, $57 \%$ (185) não haviam publicado a chamada pública, $37 \%$ (120) publicaram a chamada, mas não haviam assinado o contrato de aquisição, $2 \%$ (7) publicaram a chamada pública, assinaram o contrato, mas ainda não haviam recebido os produtos e $4 \%$ (14) publicaram pelo menos uma chamada, receberam os produtos, mas ainda não haviam realizado o pagamento aos produtores.

Com relação ao percentual dos recursos utilizados para a compra em 2010, dentre os 288 municípios que realizaram as compras em todas as suas etapas, apenas $65 \%$ (186) souberam fornecer esta informação. Os percentuais variaram de 1 a $70 \%$, segundo relato das informantes.

\section{Conclusão}

Os dados obtidos por meio deste levantamento permitiram conhecer, de maneira geral, a situação das prefeituras do estado de SP em relação à compra de produtos diretamente da agricultura familiar para a alimentação escolar com os recursos do Governo Federal. Dado que a publicação da Lei 11.947/2009 é relativamente recente, considera-se positivo o fato de $47 \%$ dos municípios já terem realizado as compras locais para o PNAE, pelo menos uma vez, desde 2009. Por outro lado, o número de municípios que ainda não publicou a chamada pública, ou que já publicou 
mas não assinou o contrato, é um número consideravel.

Para a próxima etapa, sugere-se que seja feita uma avaliação qualitativa do processo de implementação das compras locais, pois é necessário conhecer, em profundidade, o que está acontecendo para a não publicação das chamadas e a não assinatura do contrato nos municípios. Onde a compra já está sendo efetivada, é importante conhecer a porcentagem dos recursos que está sendo utilizada e determinar se estão sendo adquiridos produtos de acordo com as recomendações do FNDE, os quais devem ser gêneros alimentícios básicos, de acordo com os hábitos alimentares, a cultura e tradição alimentar da localidade, pautando-se na sustentabilidade e diversificação agrícola da região.

Recebido em: 22/03/12 Versão final apresentada em: 20/04/12 Aprovado em: 04/07/12 